\title{
Exploration and Practice of the Cross Paradigm Between Science and Engineering for Artificial Intelligence New Engineering Education Experimental Class in Local Universities
}

\author{
Xinliang Cao ${ }^{1, *}$, Ziqi Dang ${ }^{2}$ and Hongxia Yang ${ }^{3}$ \\ ${ }^{1}$ School of Physics and Electronic Information, Yan'an University, Yan'an, Shanxi 716000, China \\ ${ }^{2}$ Dean's Office, Yan'an University, Yan'an, Shanxi 716000, China \\ ${ }^{3}$ School of Architecture, Yan'an University, Yan'an, Shanxi 716000, China \\ *Corresponding author.Email: Caoxinliang874@163.com
}

\begin{abstract}
This paper aims to explore the effective way to train interdisciplinary talents on artificial intelligence and lays a preliminary foundation for the establishment of artificial intelligence major. Based on the three elements of the innovators who develop ecology and environment, this paper centers on "creating the shared platform and innovation management system", focuses on "artificial intelligence and application" and applies "the artificial intelligence experimental class" on a trial basis. In addition, the paper studies the teaching organization form from the perspective of "tutor system and its project type", builds technology innovative engineering education organization which is operated in "experimental classes paradigm" characterized by "one entity and two combinations". The experiment of two sessions on students proves this paradigm plays an obvious role in improving students' innovation ability, which can be used as a reference for the education practice of artificial intelligence new engineering talents in similar universities.
\end{abstract}

Keywords: local colleges, new engineering, experimental classes, organizational model

\section{INTRODUCTION}

At present, in the practice of training engineering talents in local colleges and universities, some problems do not correspond to the training of innovative artificial intelligence personnel, which are shown in the following aspects:

(1) In traditional higher engineering education, there are some problems such as specialization differentiation, knowledge fragmentation, experiment formalization and method simplification. This is not in line with the requirements of "establishing a new structure of disciplines and specialties, paying attention to the new quality of education and teaching, establishing a new concept of engineering education, creating a new system of classified development, and exploring a new mode of talent training" required by the upgrading and transformation of traditional engineering majors by new engineering construction. [1].

(2) The problem of interdisciplinary platform and weak environmental support in engineering education[2]. The current situation is that local science and engineering universities are divided into Department of Science, Engineering, etc., and the Department of Engineering is subdivided into Schools of Automation, Communication, Optoelectronics, Computer Science, Software, etc., under which there are several departments. Similarly, the
Department of Science is divided into the School of Mathematics, the School of Physics and the School of Chemistry. The school is also divided into several departments or second-level disciplines. Not only are there few exchanges between departments and colleges, but also different departments and subjects in the college. There is little communication among disciplines, and there is a lack of opportunities and cooperation platforms for interdisciplinary exchange and learning

(3) The problem of insufficient effectiveness of the educational organization model of interdisciplinary Engineering. Although "Innovation and Entrepreneurship Colleges" and other similar institutions have been established in local universities, these institutions often play a role in supervising and inspecting colleges' participation in the innovation and entrepreneurship competition. They are specifically responsible for university-wide training and process management of engineering students' innovation and entrepreneurship ability. They do not play a proper role in resource allocation, guiding and regulating the cultivation of innovative engineering talents.

In view of the shortages of engineering talents training in local universities, this paper tries to solve the problem of the transition and advance training of new engineering talents in artificial intelligence, and tries to popularize a kind of interdisciplinary artificial intelligence. 


\section{INNOVATIVE THINKING AND CONCRETE MEASURES OF THE TRAINING PARADIGM OF INNOVATIVE TALENTS IN EXPERIMENTAL CLASS}

\subsection{Research and practice of "Experimental class" innovation talent training paradigm}

Around the three elements (Fig. 1) "technical innovators to develop the ecological and environmental knowledge, creative thinking, and different driving force", via deepening the research on "cross" of technology integration mechanism, studying and implement effectiveness measures to stimulate the external motivation and internal teaching vitality of innovative engineering education. To optimize the curriculum system[3] and planning appropriate teaching organization form. Promoting students to master technical knowledge and improving their creative thinking. The effectiveness and function of organizational management in cultivating innovation ability are verified by teaching practice feedback.

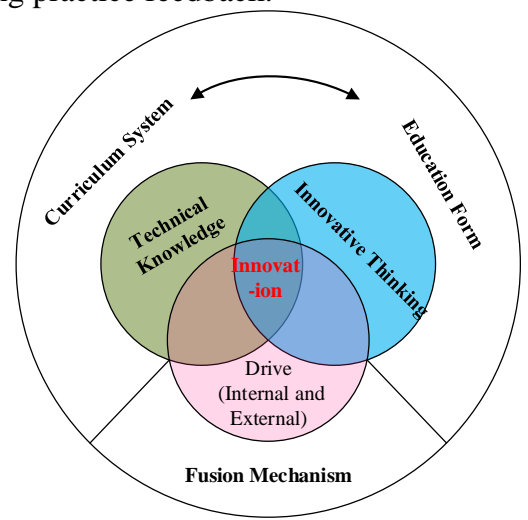

Figure 1. Innovators cultivate three elements of ecology and environment

\subsection{Specific measures for project research and practice}

\subsubsection{Strengthen the function of "Innovation and Entrepreneurship College"; Optimize the external environment and conditions of "science and engineering crossover" experimental class [4].}

Improving the construction of engineering technology research center, contact Huawei Big data $R \& D$ center in Yan'an. We will develop the development of software R\&D center and other platforms, establish the sharing system of "science and technology crossing" practice innovation platform, comprehensively expand the open scope of experimental teaching centers for various majors, and create a good external environment for students' innovation. On the premise of platform construction, the measures of training for innovative engineering talents should be standardized. The efforts should be put into four aspects: First, the basic quality of innovators should be cultivated. Second, the method of product iteration should be learned. Third, it is necessary to master the unavoidable process of hard technological creation, including from concept to design, to verification, from small batch to mass production. Finally, learn to think systematically. Apply systems thinking to clarify and solve key sub-problems in the entrepreneurial process. It is necessary to give full play to the main role of "innovation and Entrepreneurship College" in engineering innovation ability education. Through advancing with the times of the standardized system to promote the innovation of new engineering personnel training model $[1,5]$.

\subsubsection{Renovate and upgrade the training} program of "Li Fuchun Artificial Intelligence Innovation Experimental Class" in our school to stimulate the inner vitality of innovative talent training

To formulate the reform of "artificial intelligence + industry direction" for the training of innovative engineering talents with interdisciplinary knowledge and technology [6-8]. Try out the course system of "Humanistic thought, Politics, management and Art + mathematical Foundation + Three theories + Technical tools" as the general knowledge of artificial intelligence. Major elective direction corresponds to the direction of industrial development. The training scheme of the experimental class is revised with the characteristics of the combination of general and specialized courses, so as to dilute the disciplinary and professional boundaries[9]. To strengthen the grasp of basic knowledge theory of mathematics and physics. It continuously penetrates the three theories of cybernetics, system theory and information theory. To solve the separation of engineering from arts and sciences, the loss of important humanities, science support and interdisciplinary opportunities, and meet the requirements of new engineering intersections (Fig. 2). The courses of "Critical Thinking" and "Writing and Communication" are offered to cultivate students' critical thinking and communication writing skills. According to the scientific planning of the employment methods for the instructors of experimental classes, teachers of innovative experimental classes are selected through the combination of on-campus and off-campus employment and the combination of enthusiasm and ability. A variety of incentive policies will be adopted to encourage teachers who have the expertise in a certain field of ARTIFICIAL intelligence or have the title of associate professor or above, who have relatively fixed research directions and are enthusiastic to guide students to participate in the innovative practice guidance of students in the artificial intelligence experimental class. 


\subsubsection{Strengthen the guidance and regulation of the teaching practice of "project style and tutorial system".}

(1) Through the project carrier[10], mathematics, science and engineering foundation are integrated, as well as humanities, society, management, art and other related courses. Improve the audit system of practical training projects, employ expert teams to guide design teaching projects. The "4C key skills" of engineering college students, namely Cooperation, Communication, Creativity and Critical Thinking, are carried by projects as the carrier, as shown in Fig. 3.

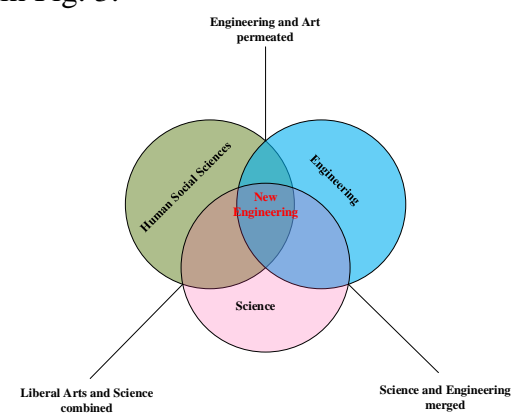

Figure 2. New engineering disciplines cross new requirements

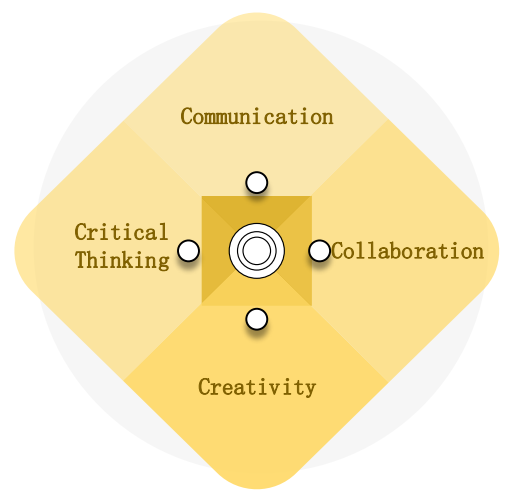

Figure 3. 4C capability structure diagram

(2) The guidance behavior of the tutor was standardized, and strict training was carried out in accordance with each stage of "raising questions -- designing and revising schemes -- collaborative exploration -- creating works -displaying and communicating -- evaluation and improvement".

Among them, in the process of raising questions, improve students' ability to observe the world, think in relation and ask questions. It can solve the embarrassing situation that there are many problems of good construction and few problems of bad construction in current education, and improve students' social responsibility at the same time. In the process of designing and revising the scheme, students need to interdisciplinary thinking, design as a whole, select methods and form solutions. Project teams work together and each person can offer a different perspective on an issue from a different perspective. A complex problem can be solved through teamwork and integration of views. In the process of completing the project, students are required to seek for a variety of solutions and creatively practice, design products, make products, complete time management and project management. In the process of communication and presentation, students are given opportunities to summarize, express academically, think critically and communicate effectively. In the process of reflection and improvement, students need to have a dialogue and in-depth analysis with their peers. Solid promotion of project learning this "difficult and complex" inquiry learning process to cultivate students' diversified abilities and qualities that are difficult to complete in traditional teaching.

(3) To guide and carry out innovative educational activities in flexible and diverse forms, fully mobilize students' interest in learning and cultivate their ability to cross boundaries.

Guide students to complete the project as a team, guide students to carry out the innovation practice of "artificial intelligence + certain application field" related projects, such as intelligent car system, intelligent recognition of human features, machine vision, wireless PLC control system, robot assembly and design, intelligent agricultural system design, intelligent transportation system design, intelligent home system design, etc., and obtain credits with explicit marking achievements. To mobilize students' interest in learning and stimulate students' enthusiasm for innovation by means of performance of project achievements and guidance of outstanding seniors; Improved AI general knowledge skills, respect for individual innovation and development, improving the capacity of crossover. Create innovative products to connect the seemingly unrelated points, push the "cross" of technology team spirit training education work. Timely organize innovation design competition, such as robot competition and other activities to develop and open up for social needs. The fourth class is characterized by interdisciplinary, project-based learning, results-oriented innovation, and diversified open space and time.

\subsubsection{Establish a scientific evaluation system and form the feedback incentive mechanism}

The evaluation is carried out at different levels, centering on the realization of "three-dimensional" goals of knowledge and skills, process and method, emotion, attitude and values. It is proposed to establish three levels of evaluation standards, and implement three types of evaluation: summative evaluation, diagnostic evaluation and formative evaluation. The evaluation results are timely fed back to the teachers and students of the experimental class, the teaching methods are timely adjusted, the closedloop rolling optimization will be implemented, and a relatively stable teaching organization and talent cultivation mode are formed. 
A diversified student evaluation system has been developed for the "science and engineering Crossover" experimental class. In the subsequent teaching activities, those who are absent from the class for many times, have no strong sense of initiative innovation or have little interest in artificial intelligence will be regarded as leaving the class. For the students outside the class who have strong innovation ability and strong interest in artificial intelligence, they can be admitted to the experimental class upon the recommendation of the tutor with the presentation of relevant performance proof and the approval of the Institute of Innovation and Entrepreneurship. The students in the experimental class will not affect the choice of exchange training and change majors. Students of innovative experimental class are given priority in training resources and opportunities. The school will provide qualified teachers and facilities for the class, timely organize internship and study outside. Priority shall be given to obtaining postgraduate exemption qualification, and priority shall be given to recommending provincial and national innovation projects on the basis of university-level innovation and entrepreneurship programs for college students. Enjoy the exchange and learning opportunities for external experts and enterprise engineers to give lectures and lectures. Give priority to recommending students of experimental classes to participate in professional competitions, timely commend and encourage outstanding teachers and students emerging from innovative education.

\section{THE ORGANIZATION MODE OF SCIENCE AND ENGINEERING CROSS EXPERIMENTAL CLASS OPERATION}

Optimize the innovation environment according to the interdisciplinary nature of artificial intelligence and the development trend of artificial intelligence industry. To promote the interdisciplinary integration of automation, electronic information engineering, communication engineering, information and computing science, computer science and technology, software engineering, internet of things engineering, process control and physics in our university. By combining artificial intelligence with the direction of industry, an organization model of "one entity, multiple integration and two combinations" of science and technology is constructed in terms of organization operation, as shown in Fig. 4.

\section{TRAINING PRACTICE OF INTERDISCIPLINARY EXPERIMENTAL CLASS OF SCIENCE AND TECHNOLOGY}

\author{
4.1. The "Li Fuchun Artificial Intelligence \\ Experimental Class" with "Science and \\ Technology Crossover" has been established, \\ and the preliminary implementation plan has \\ been formulated
}

The experimental class is selected from nine majors: Automation, Electronic Information Engineering, Communication Engineering, Information and Computing Science, Computer Science and Technology, Software Engineering, Internet of Things Engineering, Physics and Process Control. The "Li Fuchun Artificial Intelligence Experimental Class" are formed by selecting the best students through individual application, department examination, written test and interview. Try to offer 6 compulsory courses, 9 credits; At the same time, the tutorial system and project-based teaching system are implemented. One-stop follow-up guidance by the tutor, responsible for the big innovation projects, all kinds of professional innovation competitions and graduation design guidance. Project-based teaching counts for 7 credits, and innovation experimental class courses total 16 credits Since the establishment of the experimental class, The Intensive Teaching and Training of Artificial Intelligence, Python Programming Language Design, Intelligent Home Training, Cloud Computing and other courses have been completed. "A Tentative Program of Teaching Management of $\mathrm{Li}$ Fuchun Artificial Intelligence Innovation Experimental Class of Yan'an University" has been formulated.

\subsection{Teaching is organized in various ways, such as network and lecture, focusing on cultivating students' ability of life-long learning}

The experimental class took the form of special lectures to broaden the students' knowledge horizon and understanding of the frontier of new forms of business development. They were invited to hear the lecture "Human Consciousness through Eye Movement" given by Dr. Zhang Yun of Xi'an Jiaotong University, "Application of Machine Vision and Influence of Lighting" given by Professor Kang Yimei of Beijing University of Aeronautics and Astronautics, and seven academic reports on "Artificial Intelligence and Smart City" given by Dr. Wang Xinlei, vice President of Deep-Blue Science and Technology.

With the advantage of online learning, we have created a "Learning and Communication Group of Dreamlike Space Tribe" and pushed more than 40 pieces of information. Fundamentals of Machine Learning, Fundamentals of Deep Learning, Convolutional Neural Network, Deep Learning Application (Computer Vision), Deep Learning Application 
(Natural Language Processing), Circular Neural Network, 11 artificial intelligence online courses jointly created by Baidu and the Chinese Academy of Sciences were opened in connection with online learning permissions.

\subsection{Improve the condition of practice education and set up two training platforms}

36 sets of MCU development kits and 12 "smart cars" were purchased. Engineers from Huawei Institute of Network Technology and Huaqing Foresight Education Group were invited to give lectures and practical training for the experimental class by taking full advantage of the schoolenterprise cooperation between Huawei Institute of Network Technology and ICT Industry and education Integration Base. At present, Huaqing Vision Education Group has sent corporate mentors to carry out two periods of practical training on "intelligent tracking car" and "cloud computing". The completed " Big data Innovation Platform of Yan'an University " has been approved to become two training platforms of "Yan'an Engineering Technology Research Center".

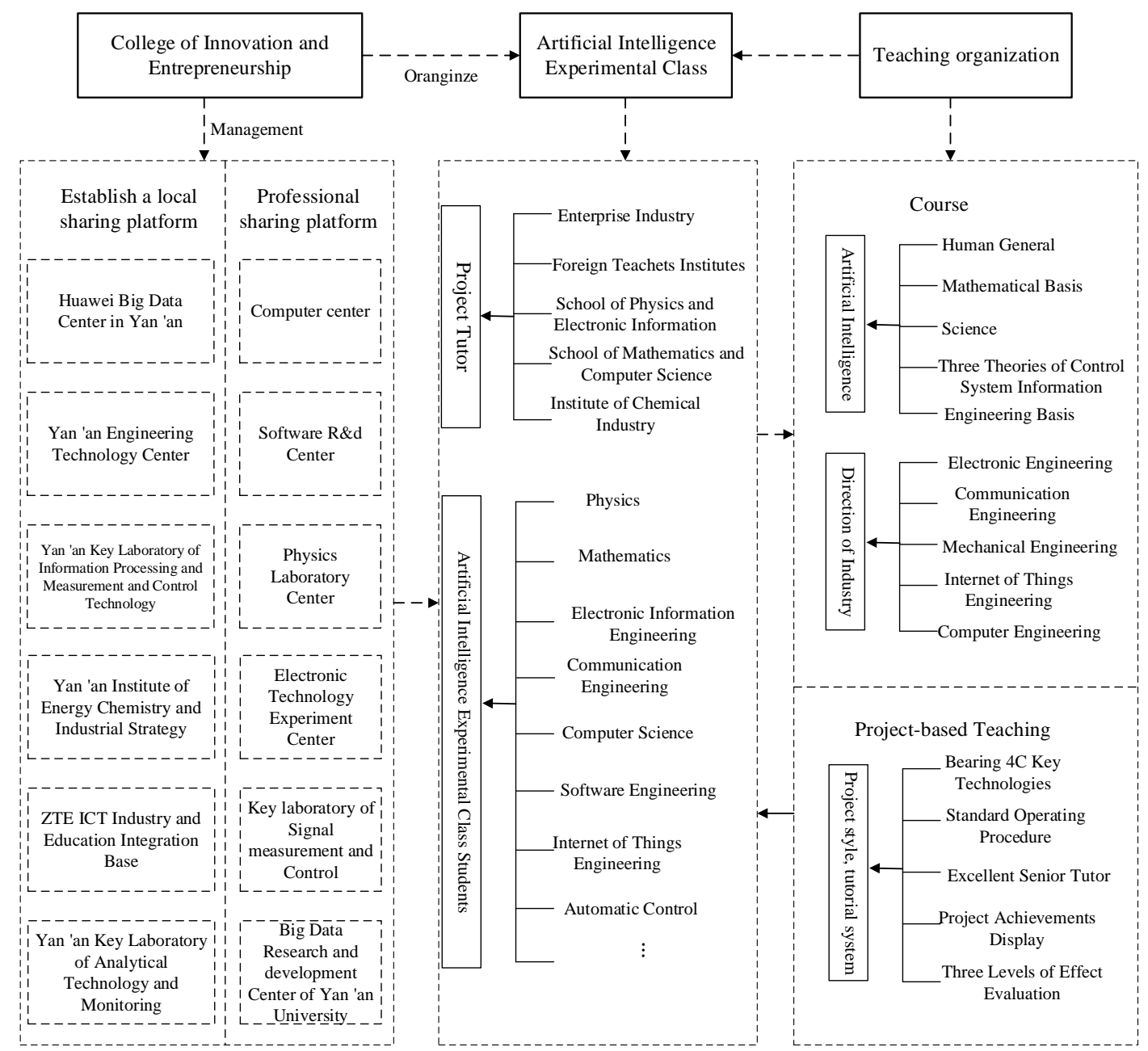

One Entity

Multiple Fusion

Two Combination

Figure 4. "One entity, multiple integrations, two combinations" of science and technology cross innovative engineering education organization model diagram 


\subsection{Select and employing project-based teaching tutors and complete mutual selection between teachers and students}

The selection conditions of project tutors were formulated, and 8 teachers of electrical majors were employed as project teaching tutors. Each teacher can bring 3 5 students. The students can follow the tutor's research topics to carry out the innovation practice of "artificial intelligence + an application field" related projects. Designate one school adviser for each project; The tutor is responsible for contacting a well-known expert, a professor, or an enterprise engineer as the tutor to guide students' innovative practice activities.

\section{PRELIMINARY RESULTS OF TALENT TRAINING OF SCIENCE AND TECHNOLOGY CROSS EXPERIMENTAL CLASS}

\subsection{Students' learning enthusiasm has been stimulated, and the atmosphere of spontaneous inquiry learning has taken shape initially}

Some students have participated in research topics such as "Research on the Identification of Peony Flower Species Based on convolutional neural network" and "Research on the Image segmentation Method of Shandan flower based on convolutional neural network". Some tutors have provided guidance and given the topics to participating in international professional competitions: Automatic generation of Tibetan poems and ancient poems based on LSTM network; Generate images from text; Generate Chinese fonts automatically based on GAN; Image repair based on deep learning; Visual question answering system, etc. At present, three students have made online academic communication reports.

\subsection{Students' innovation ability has been improved rapidly}

Since the establishment of "Li-Fuchun Artificial Intelligence Innovation Experimental Class" in October 2018. Students' innovative ability and practical abilities have been rapidly improved through centralized teaching, scientific and technological reports, project-based teaching and other forms of learning and training. Respectively, the six students in the class won the third prize in the second China University Intelligent Robot Creative Competition, the third prize in the sixth National College Students Engineering Training Comprehensive Ability Competition in Shaanxi Competition, the third prize in the Provincial selection of Shaanxi Competition in 2018 National College Students "Internet + " and the sixth Discovery Cup National College Students Internet Software Design Competition and the third prize in Shaanxi Competition in 2019 National College Students Electronic Design Competition, which greatly enhanced the students' confidence and consciousness of improving their innovation ability.

\section{CONCLUSION}

Based on the three elements of innovator cultivate ecology and environment, the "experimental class paradigm" of "one entity, multiple integrations and two combinations" was constructed for the operation of interdisciplinary innovative engineering education organization. It has enriched the connotation of new engineering education, flexible the form of cross-talent training. So that the experimental class students' innovation ability, cooperation spirit, independent learning ability, ability to deal with complex problems and perseverance to meet the requirements of engineering graduation gradually and highly achieved.

\section{ACKNOWLEDGMENTS}

The author acknowledges the funding support from the Yan'an University Graduate Education and Teaching Reform Research Project "Engineering Numerical Analysis' Curriculum Project-based Teaching Reform and Practice" (YDYJG2018029), and Shaanxi Province's second batch of new engineering research and practice projects "Local Colleges Industrial-Industry Intersection" innovative engineering education organization Model Research and Practice" and Yan'an University Continuing Education Reform Project "Exploration and Practice of Adult Higher Education Combining Vocational Qualification Certification and On-the-job Training" (YDJY2015-06).

\section{REFERENCES}

[1] Yinghui, C., Thinking and Exploration on the Construction of new engineering System and Mechanism. Higher Education Exploration, 2019(01), pp. 37-39+117.

[2] Yun, Z., L. Lijuan, Y. Wenbin, C. Shuting, Practice of Multidisciplinary Integration of Emerging Engineering Education. Research in Higher Education of Engineering, 2019(02), pp. 50-56.

[3] Li, H., F. Xiaoyun, S. Ailing, L. Jun, A Study on the Construction of Interdisciplinary Course Under the Background of Emerging Engineering Education. Research in Higher Education of Engineering, 2020(02), pp. 31-40.

[4] Yiqiu, W. and Z. Yibo, The Consideration of the "Applied Science". HIGHER EDUCATION OF SCIENCES, 2015(01), pp. 1-13+28. 
[5] Jian, L., The Construction of China's New Engineering Disciplines for the Future. TSINGHUA JOURNAL OF EDUCATION, 2017. 38(02), pp. 26-35.

[6] Xue, W., H. Haiyan, L. Ping, Z. Lei, Research on Artificial Intelligence Talent Education: Review, Comparison and Prospect. Research in Higher Education of Engineering, 2020(01), pp. 42-51.

[7] Haisheng, Z., Problems and strategies to artificial intelligence talent training in colleges and universities in China. Journal of Higher Education Management, 2020. 14(02), pp. 37-43+96.

[8] Tingting, L., S. Zhiguo, J. Yanli, The Hotspots and Trends of Literature Research on Artificial Intelligence Teaching in China. HIGHER EDUCATION OF SCIENCES, 2019(06), pp. 98-107.
[9] Binsheng, L., C. Mengli, L. Ying, Exploration on the Large-scale Training Mode of ElectronicInformation Specialities JOURNAL OF EEE, 2020. 42(01), pp. 18$20+64$.

[10] Dabing, L., Z. Zutao, P. Yajia,T. Huaiwen, Exploration of Teaching Mode of Engineering Course Combining MOOC and Project-based Teaching.

Research in Higher Education of Engineering, 2020(02), pp. 164-168. 